Relations industrielles

Industrial Relations

\title{
Le Travail, par Pierre Badin, Gilbert Blardone, Joseph Folliet et Henri Vial, collection « Savoir pour Agir », Chronique Sociale de France, Lyon, 1964, 271 pages.
}

\section{Jean Michaud}

\section{Volume 19, numéro 4, 1964}

URI : https://id.erudit.org/iderudit/027537ar

DOI : https://doi.org/10.7202/027537ar

Aller au sommaire du numéro

Éditeur(s)

Département des relations industrielles de l'Université Laval

ISSN

0034-379X (imprimé)

1703-8138 (numérique)

Découvrir la revue

Citer ce compte rendu

Michaud, J. (1964). Compte rendu de [Le Travail, par Pierre Badin, Gilbert Blardone, Joseph Folliet et Henri Vial, collection " Savoir pour Agir ",

Chronique Sociale de France, Lyon, 1964, 271 pages.] Relations industrielles /

Industrial Relations, 19(4), 530-530. https://doi.org/10.7202/027537ar

Tous droits réservés (C) Département des relations industrielles de l'Université Laval, 1964
Ce document est protégé par la loi sur le droit d'auteur. L’utilisation des services d'Érudit (y compris la reproduction) est assujettie à sa politique d'utilisation que vous pouvez consulter en ligne.

https://apropos.erudit.org/fr/usagers/politique-dutilisation/ 
L'année sociale 1963, par Guy Spitaels, Université libre de Bruxelles, Institut de sociologie. Bruxelles, 1964, 360 pages.

A chaque année, depuis 1960, l'auteur publie une synthèse de la vie sociale belge.

Cet ouvrage est divisé en quatre parties: a) La vie législative; b) la vie paritaire; c) la vie syndicale et la pensée des partis politiques; d) le visage social de l'Europe des six.

Les faits, les évènements, les attitudes sont expliqués et placés dans leur contexte. C'est une besogne périlleuse que d'écrire I'histoire au jour le jour.

Pour un étranger qui n'a pas le loisir de suivre de près ce qui se passe en Belgique, il est difficile de porter un jugement sur I'objectivité de l'auteur. Quelle qu'elle soit, il est quand même intéressant et utile de lire une telle synthèse. A partir d'une vue globale, il est ensuite possible à quiconque d'étudier plus à loisir l'un ou l'autre des points mentionnés par l'auteur.

Nous souhaitons qu'un Conadien aura le courage de $M$. Spitaels et nous présentera. un ouvrage du genre sur la vie sociale de notre pays.

\section{Gérard Dion}

Le Travail, par Pierre Badin, Gilbert Blardone, Joseph Folliet et Henri Vial, collection \& Savoir pour Agir », Chronique Sociale de France, Lyon, 1964, 271 pages.

Ce livre, oeuvre de spécialistes de différentes disciplines comprend trois porties soit: 1) Survol de /'histoire du travail; 2) La condition du travail contemporain; 3) Regards chrétiens sur le trovail.

Le survol de l'histoire, que nous livrent les auteurs, nous est présenté par le biais du progrès technique, lequel influe sur les conditions de travail, comporte la division du travail avec ses effets socioux. L'esclavage, le servage et le prolétariot sont les charnières qui soutiennent l'idée de l'exploitation de l'homme par I'homme. Ce survol historique se termine par une étude de l'évolution du travail de notre temps, on y note la prédominance du salariat urbain et de la grande entreprise, la croissance du secteur tertiaire et le caractère expansionniste de l'économie.
Cette première partie a le mérite d'être d'intérêt universel, d'aborder succinctement les traits essentiels de l'histoire du trovail et de présenter les foits clairement et logiquement.

Le corps de l'ouvrage est constitué par la description des conditions technologiques, sociales et juridiques du travail contempcrain. Les conditions technologiques font l'objet d'un bref exposé en trois points: machinisme, organisation scientifique du travail et automatisation. Les conditions sociopsychologiques du travail et le travail féminin traités respectivement dans les chapitres IX et XI sont d'un intérêt particulier tont par leur contenu que leur traitement. Les conditions juridiques présentent un intérêt plus spécifiques car, si l'on fait exception de quelques pages sur I'O.T.J. et les autres institutions internationales du travail, les auteurs abordent uniquement le système juridique français de relations de travail. Cette section constitue une introduction concise et valable à la législation ouvrière française.

Lo dernière partie de l'ouvrage, portant sur les problèmes généraux posés par le travail à la morale, à la philosophie et à la théologie, constitue, à notre avis, la partie la plus originale de l'ouvrage. Les auteurs nous donnent des notions précises sur la nature du travail, ses relations avec la nature, I'homme et 'Dieu; ils précisent en outre les conditions matérielles, psychologiques et morales du travail. Cette section est étayée par des textes pontificaux sur divers aspects du travail, textes qui sont analysés et interprétés avec justesse.

Cet ouvrage est un instrument polyvalent qui s'adresse d̀ la fois aux cercles d'études et groupes de discussion et aux jeunes, étudiants, trovailleurs ou syndicalistes; il peut même constituer un memento pour des hommes d'action. II s'adresse à ceux qui ont besoin d'une introduction pratique et suc.. cincte aux réalités du monde du travail parce qu'il traite d'une foule de questions et aiguise I'intellect. II demeure une introduction qui se doit d'être supplémentée grôce à la bibliographie excellente, divisée par sujet, que l'on retrouve aux pages 257 à 261. La troisième partie: Regards chrétiens sur le travail, est la plus valable pour ceux qui ont déjà quelques connaissances de cette réalité complexe qu'est le travail. Sous une forme concise et facile les auteurs nous apportent des notions qu'il est important $\dot{d} \epsilon$ posséder et de garder en mémoire. 